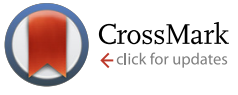

Cite this: Med. Chem. Commun., $2015,6,879$

Received 18th November 2014, Accepted 6th March 2015

DOI: $10.1039 / c 4 m d 00526 k$

www.rsc.org/medchemcomm

\section{Membrane-interacting properties of the functionalised fatty acid moiety of muraymycin antibiotics $\dagger$}

\author{
Oliver Ries, ${ }^{a}$ Christian Carnarius, ${ }^{a}$ Claudia Steinem ${ }^{a}$ and Christian Ducho*ab
}

\begin{abstract}
Functional insights into bioactive natural products with medicinal potential are often hindered by their structural complexity. We herein report a simplified model system to investigate the functional significance of a structural motif of biologically potent muraymycin antibiotics of the A-series. These compounds have a highly unusual $\omega$-guanidinylated fatty acid moiety, which has been proposed to mediate membrane penetration, thus enabling the interaction of A-series muraymycins with their intracellular target MraY. Our assay was based on a synthetic conjugate of this fatty acid structure with a negatively charged fluorophore lacking membrane permeability. Using this conjugate, immobilised giant unilamellar lipid vesicles and confocal laser scanning fluorescence microscopy, we demonstrated that the attachment of the $\omega$ - $N$-hydroxyguanidinyl fatty acid unit led to an enhanced uptake of the fluorophore into the vesicles. This represents the first experimental evidence of this unusual structural motif's functional relevance for the parent natural product, which may support the future design of novel muraymycin analogues.
\end{abstract}

\section{Introduction}

Bacterial strains with resistances towards established antibiotics continue to emerge. However, only very few new antibacterial agents have been developed in recent years. ${ }^{1,2}$ It is therefore highly desirable to identify novel antimicrobial compounds displaying new or yet unexploited modes of action. Starting with the development of the penicillins in the 1940s, natural products and their analogues have served as clinically useful antibiotic agents. Thus, one may assume that naturally occurring antibiotics will probably play a key role in overcoming the current lack of new antibacterials for clinical use. This will include the identification of such compounds, their total synthesis for structure-activity relationship (SAR) studies, and also their functional elucidation. Due to the structural complexity of many natural products though, their functional analysis is often not trivial and requires time-consuming multi-step syntheses of suitable molecular probes.

Nucleoside antibiotics represent a class of natural products targeting cell wall biosynthesis. ${ }^{3,4}$ Antibacterially active nucleoside antibiotics interfere with peptidoglycan assembly

\footnotetext{
${ }^{a}$ Georg-August-University Göttingen, Department of Chemistry, Institute of Organic and Biomolecular Chemistry, Tammannstr. 2, 37077 Göttingen, Germany.E-mail: christian.ducho@uni-saarland.de

${ }^{b}$ Saarland University, Department of Pharmacy, Pharmaceutical and Medicinal Chemistry, Campus C2 3, 66123 Saarbrücken, Germany

$\dagger$ Electronic supplementary information (ESI) available: ${ }^{1} \mathrm{H}$ and ${ }^{13} \mathrm{C}$ NMR spectra of synthesised compounds. See DOI: 10.1039/c4md00526k
}

via inhibition of the bacterial membrane protein MraY, a key enzyme in the intracellular part of peptidoglycan formation. ${ }^{5-9}$ As the active site of MraY is located at the cytosolic side of the bacterial membrane, MraY inhibitors need to be able to penetrate the bacterial cell wall and the plasma membrane. Streptomyces-produced muraymycins (e.g. muraymycins A1 1 to A5 5, B5 6, C4 7 and D2 8, Fig. 1) represent one subclass of nucleoside antibiotics. They show promising activity against Staphylococcus aureus and Enterococcus strains via inhibition of MraY. ${ }^{10}$

Some SAR data have already been reported for muraymycins and their analogues. ${ }^{11-15}$ However, a structural feature of muraymycins which has only found limited attention so far is the presence of $\omega$-guanidinylated fatty acid moieties in the biologically most potent muraymycins of the Aseries. These fatty acid units are attached to the muraymycin backbone via esterification of a 3-hydroxy-L-leucine motif. Muraymycins of the B-series carry shorter and unfunctionalised fatty acids, while the fatty acid unit is missing in muraymycins of the C- and D-series. As a general rule, the A-series muraymycins show the best antibacterial activities, followed by the B-series congeners, while C- and D-series muraymycins are pronouncedly less active. ${ }^{10}$ These SAR findings might indicate (i) that the presence of the fatty acid moiety mediates membrane penetration of the otherwise polar muraymycin scaffold ${ }^{14}$ (and therefore cellular uptake of the acylated congeners) and (ii) that $\omega$-guanidinylated fatty acids, despite the polarity of the $\omega$-functionality, provide an even more pronounced membrane-penetrating effect. 


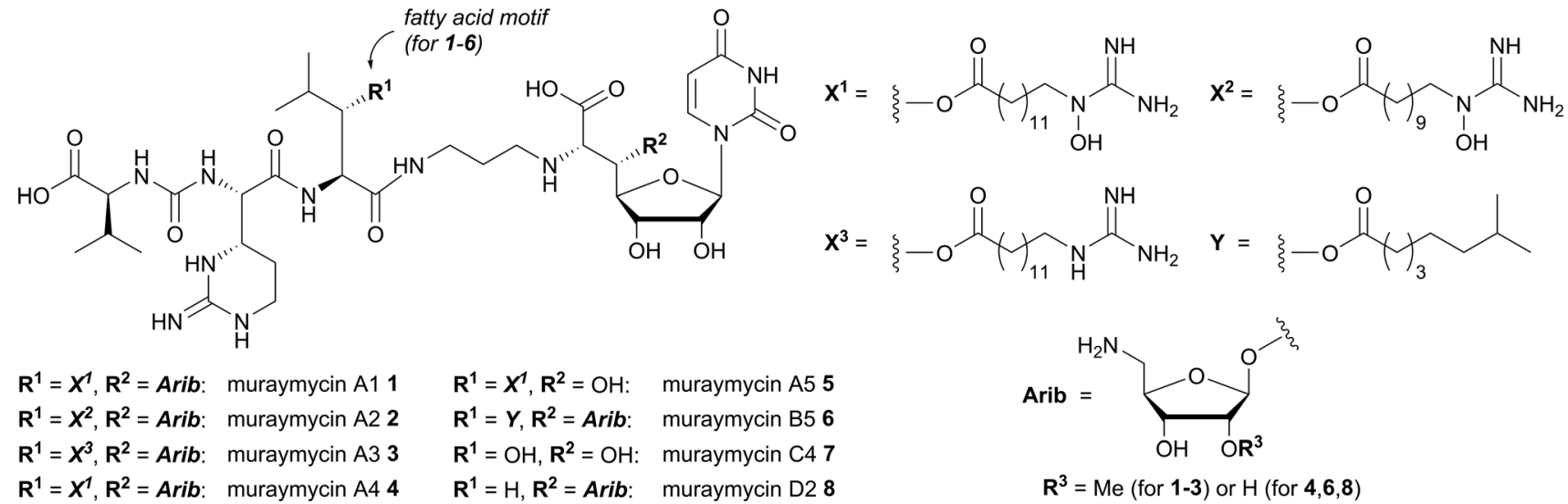

Fig. 1 Selected naturally occurring muraymycin nucleoside antibiotics 1-8.

The most obvious strategy to experimentally study this hypothesis would be to synthesise fluorescently labelled analogues of $\mathrm{O}$-acylated muraymycins and to test them for membrane interaction and permeability e.g. with lipid vesicles. However, an attached fluorophore would potentially alter the molecular properties of muraymycins to a significant degree. Furthermore, the total synthesis of muraymycin-derived fluorescent probes would be time-consuming. We therefore decided to design a pronouncedly simplified model system to assay the fatty acid moiety of muraymycin A1 1 (residue $\mathbf{X}^{\mathbf{1}}$, Fig. 1) for its ability to mediate membrane interaction and penetration. The goal was to study potential accumulation at the membrane interface and a possible increase of membrane permeability.

\section{Results and discussion}

\section{Experimental design}

The concept of the employed assay is depicted in Fig. 2. The fluorescent dye AlexaFluor 488 (AF488) was chosen as it exhibits large photostability. It was envisioned to convert a commercially available azide-labelled derivative 9 of AF488 with the propargyl ester $\mathbf{1 0}$ of the fatty acid moiety of muraymycin A1 1 (subsequently named "lipid side chain", LSC, Fig. 2B). Using the copper-catalysed version of the Huisgen alkyne-azide cycloaddition ("click"-chemistry), ${ }^{16-18}$ this should furnish AF488 LSC conjugate 11. It can then be tested if the presence of the LSC unit makes the AF488 moiety membrane-permeable, i.e. if fluorescence can be detected within lipid vesicles upon treatment with 11 (Fig. 2A). In order to ensure that the linker unit, i.e. the 1,4-substituted triazole, does not influence the low membrane permeability of the fluorescent dye, acetyl derivative 12 ("AF488 acetate") lacking the full-length LSC motif was envisioned to serve as a reference (Fig. 2B).

\section{Synthesis of fluorescent probes}

For the synthesis of AlexaFluor 488 LSC conjugate 11, propargyl ester 10 had to be prepared first (Scheme 1).
A
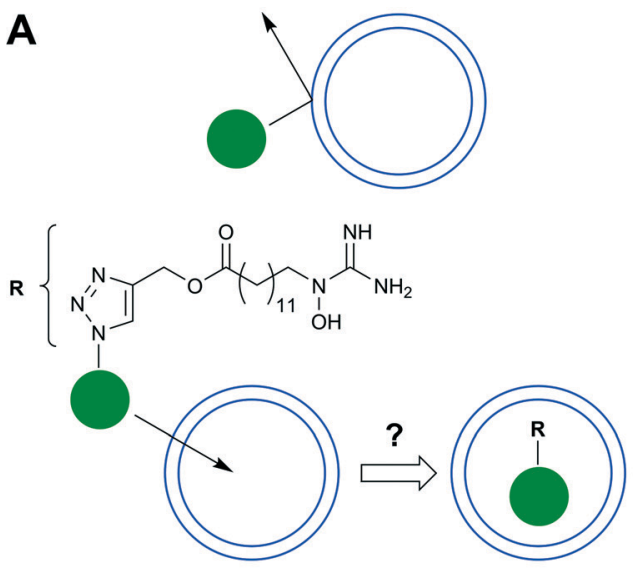

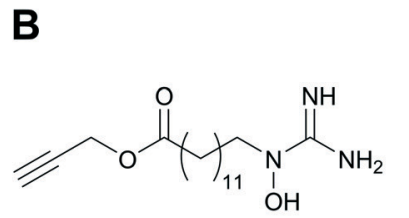

10

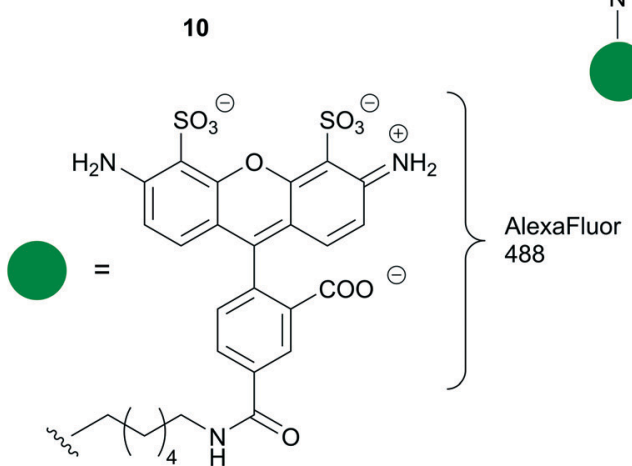

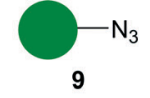<smiles>CC(CC(C)(C)CN(O)C(=N)N)C(=O)OCc1cn[nH]n1</smiles>

11

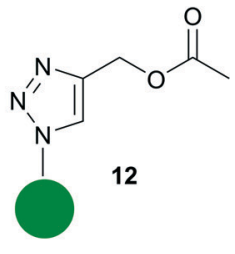

Fig. 2 A: Simplified assay system to test the influence of the fatty acid moiety of muraymycin A1 1 (LSC) on membrane-penetrating properties of an attached structure lacking membrane permeability (schematic representation). B: AlexaFluor 488 derivatives 11 and 12 conceived for the assay. 


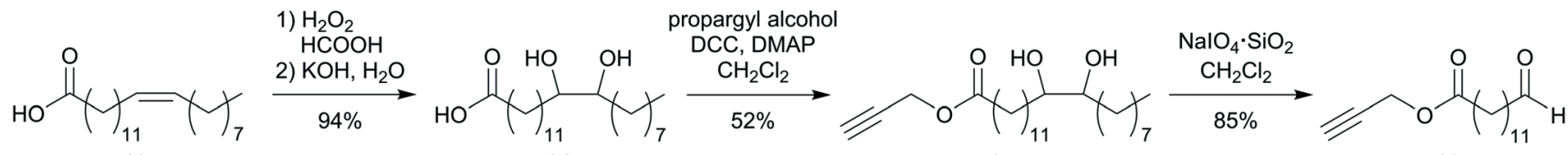

13

14

15

16
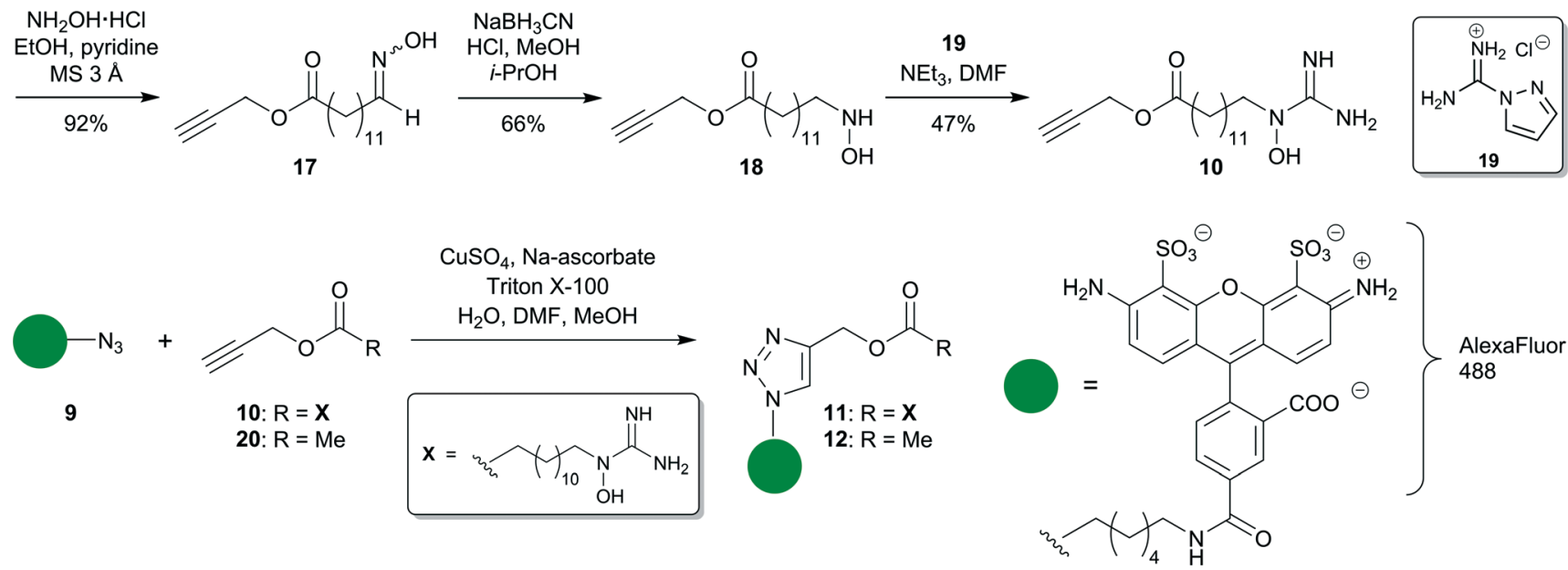

Scheme 1 Synthesis of AlexaFluor 488 derivatives 11 and 12.

Starting from erucic acid 13, epoxidation and alkaline epoxide opening gave 13,14-dihydroxy behenic acid 14 as a mixture of stereoisomers in $94 \%$ yield. Esterification with propargyl alcohol by carbodiimide activation then furnished propargylic ester 15 in $52 \%$ yield. Subsequent periodate cleavage afforded aldehyde 16, i.e. an $\omega$-functionalized tridecanoic acid propargyl ester, in 85\% yield. Aldehyde 16 was then employed in a sequence of oxime formation (product 17, $92 \%$ yield) and reduction to give $N$-alkyl hydroxylamine 18 (66\% yield for the reduction step). As part of our synthetic studies on muraymycins and their analogues, ${ }^{19-26}$ we have systematically investigated the preparation of $\mathrm{N}$-alkyl- $\mathrm{N}$ hydroxy-guanidines by guanidinylation ${ }^{27}$ of $\mathrm{N}$-alkyl hydroxylamine precursors. ${ }^{28}$ A protecting group-free method using guanidinylation reagent 19 turned out to be the best method for this transformation. Consequently, treatment of 18 with 19 gave the desired $N$-alkyl- $N$-hydroxy-guanidine 10 with high conversion, but due to difficult purification of the amphiphilic product, in a moderate yield of $47 \%$ (Scheme 1 ).

Unexpectedly, the subsequent copper-catalysed "click" reaction towards conjugate $\mathbf{1 1}$ turned out to be non-trivial. First attempts under standard conditions only gave low conversions, which we speculate to be a consequence of the amphiphilic nature of alkyne 10. Following a thorough variation of the reaction conditions, the reaction could be significantly improved by reductive in situ-generation of the copper(I) catalyst, application of the solvent system water/ DMF/methanol and addition of the detergent Triton X-100. However, due to the high costs for azide-labelled AF488 derivative 9 , the reaction could only be performed on the sub-mg scale, thus making an unambiguous determination of the yield difficult. Product 11 could be obtained after HPLC purification, and the identity of the product could be confirmed by mass spectrometry as the amount was insufficient for NMR spectroscopy. AF488 acetate 12 was prepared in an analogous manner using propargyl acetate 20 as the alkyne component for the "click" reaction (Scheme 1), and both target compounds $\mathbf{1 1}$ and $\mathbf{1 2}$ were thus available for the aforementioned fluorescence-based assay.

\section{Membrane partitioning assay}

The influence of AlexaFluor 488 LSC conjugate 11 on lipid membranes was investigated by means of fluorescence microscopy based on giant unilamellar vesicles (GUVs). GUVs composed of 1-palmitoyl-2-oleoyl-sn-glycero-3-phosphocholine (POPC), fixed to a silicon substrate via biotin-avidin interaction, were incubated with conjugate $\mathbf{1 1}$ and confocal laser scanning microscopy images were taken. The fluorescence image depicted in Fig. 3 clearly shows that conjugate 11
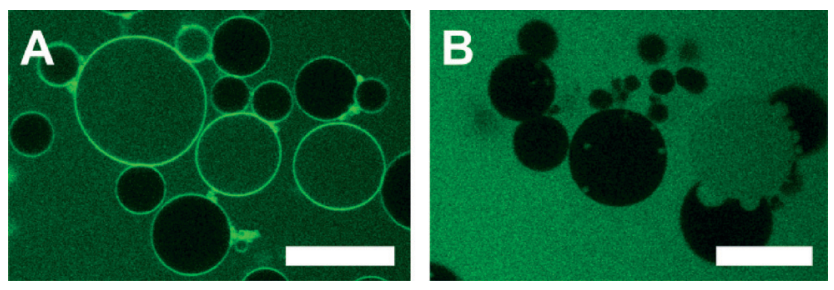

Fig. 3 A: Fluorescence image of GUVs composed of POPC after incubation with $0.8 \mu \mathrm{M}$ AF488 LSC conjugate 11 . The compound accumulates in the lipidic phase of the GUVs and is partially also localised inside the GUVs. B: Fluorescence image of POPC-GUVs after incubation with $0.8 \mu \mathrm{M}$ AF488 acetate 12 . AF488 acetate 12 does not accumulate at the membrane interface, but it is found in some of the GUVs. Scale bars (white boxes): $20 \mu \mathrm{m}, \mathrm{POPC}=1$-palmitoyl-2-oleoylsn-glycero-3-phosphocholine. 


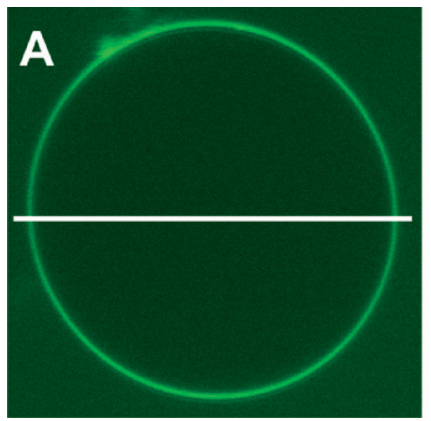

B

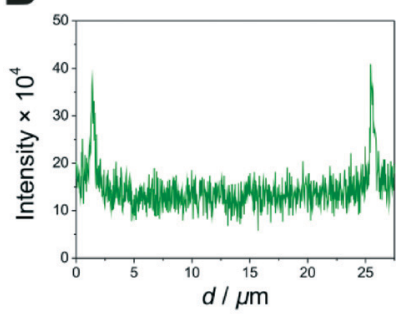

Fig. 4 A: Fluorescence image showing an individual GUV composed of POPC/POPE $(7: 3)$ with increased fluorescence intensity at the membrane interface and fluorescence intensity inside the GUV after incubation with AF488 LSC conjugate 11. B: Line profile along the white line shown in A clearly demonstrating the fourfold increase in fluorescence intensity at the lipid membrane. POPC = 1-palmitoyl-2oleoyl-sn-glycero-3-phosphocholine, POPE = 1-palmitoyl-2-oleoylsn-glycero-3-phosphoethanolamine.

accumulates in the lipid membrane (also see Fig. 4). Part of the GUVs is also filled with the conjugate 11. As a control, the same experiment was performed with AF488 acetate 12 lacking the fatty acid moiety. In this case, no enrichment of the dye in the lipid membrane was observed. To quantitatively analyse the number of GUVs which were filled with the fluorescent conjugate, we defined a GUV as dye-filled if $F / F_{0}$ $>0.5$, with $F$ being the intensity of the GUV interior and $F_{0}$ being the background intensity. $24 \%$ of the POPC GUVs were filled with AF488 LSC conjugate 11 after 40 min and only 6\% after incubation with AF488 acetate 12 (with the entire distribution for $F / F_{0}>0.5$ being taken into account, Fig. 5A). It should be noted that values $F / F_{0}>1.0$ could be ruled out as this would have required an active transport process (equilibrium is reached for $F / F_{0}=1.0$ ). Active transport processes need external sources of energy (e.g. an electrochemical gradient or light coupling) though, and these were absent in the employed assay.

To investigate the influence of the lipid mixture on the dye distribution, we used a POPC/POPE (1-palmitoyl-2-oleoyl$s n$-glycero-3-phosphoethanolamine, 7:3) mixture to form GUVs better resembling the composition of bacterial membranes. Also for POPC/POPE membranes, an increased fluorescence intensity in the membrane interface as a result of accumulation of AF488 LSC conjugate 11 was found, leading to an almost four times larger fluorescence intensity at the membrane compared to the bulk solution (Fig. 4). $14 \%$ of the GUVs were filled with AF488 LSC conjugate 11, but only $4 \%$ in case of AF488 acetate 12 (Fig. 5B). Distribution patterns were similar to those found for the POPC GUVs (vide supra, also see Fig. 5A).

Based on the simplified model system, we were thus able to provide evidence that the fatty acid moiety of A-series muraymycins probably contributes to the accumulation of these compounds at a lipid membrane. An increased number of GUVs were filled with the lipidated fluorescent dye, which might be a result of the accumulation of the compound at
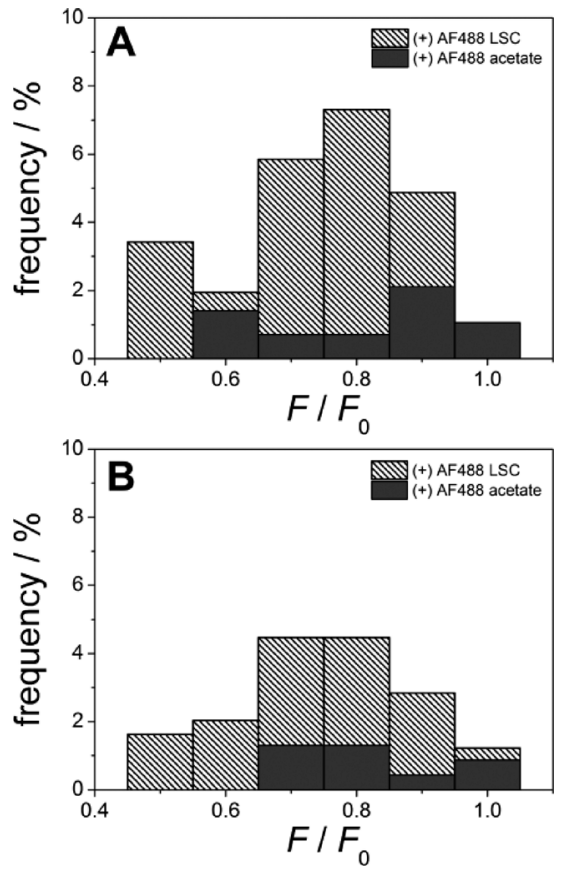

Fig. 5 A: Statistical analysis of dye-filled POPC GUVs after the addition of AF488 LSC conjugate 11 and AF488 acetate $12.24 \%$ of the GUVs ( $n$ $=410)$ were filled with AF488 LSC conjugate 11 , while only $6 \%(n=$ 283) were filled with AF488 acetate 12. B: For POPC/POPE (7:3) GUVs incubated with 11 or $12,14 \%$ of the GUVs were filled with AF488 LSC conjugate $11(n=246)$ and $4 \%$ with AF488 acetate $12(n=230)$. POPC = 1-palmitoyl-2-oleoyl-sn-glycero-3-phosphocholine, $\mathrm{POPE}=$ 1-palmitoyl-2-oleoyl-sn-glycero-3-phosphoethanolamine.

the membrane interface, which can disturb the integrity of the bilayer. From these results, we conclude that muraymycin membrane partitioning and cell entry is probably facilitated by the $\omega$-guanidinylated lipophilic side chain.

The role of guanidine moieties in membrane penetration and thus in cellular uptake processes has been widely investigated and discussed. ${ }^{29}$ Arginine-rich cell-penetrating peptides have been extensively studied, ${ }^{30-33}$ and guanidinylated cationic lipids were reported to be effective transfection agents. ${ }^{34}$ Guanidinylated dendrimers were found to display pronounced interactions with liposomal phospholipid membranes, ${ }^{35}$ and conjugates of aminoglycoside antibiotics with guanidinylated cationic lipids showed antibacterial activity. ${ }^{36}$ However, such oligo-guanidinylated systems are probably prone to cooperative or multivalency effects, and it is therefore quite remarkable that a single $\omega$-guanidinylated fatty acid motif (as in A-series muraymycins or in AlexaFluor 488 LSC conjugate 11) can enable membrane interaction and penetration as reported herein. It should be taken into account though that the $N$-hydroxylated guanidine moiety of A-series muraymycins and conjugate $\mathbf{1 1}$ is likely to have reduced basicity in comparison to non-hydroxylated guanidines.

\section{Conclusions}

In summary, we have developed an efficient and facile method to study the interaction of a naturally occurring 
structural motif with lipid membranes. Using this assay, we were able to demonstrate that the $\omega$-functionalised fatty acid moiety found in some muraymycin nucleoside antibiotics of the A-series can mediate membrane accumulation and even membrane penetration of a fluorescent dye. This represents the first experimental evidence of this unusual structural motif's functional relevance for the parent natural product. While there is no close structural relation of the employed fluorophore and the natural product scaffold, the relative ease of our method will allow to test a significant number of fatty acid motifs for their potential to mediate membrane accumulation and penetration. This will be important to elucidate the relevance of the $\omega$-substituent as well as of the length of the lipophilic moiety, i.e. the supposed interplay of polar $\omega$-functionalisation and lipophilicity. Based on the results reported herein, we will therefore synthesise and investigate varying fatty acid units found in the muraymycin family as well as non-natural congeners with respect to different chain lengths and functional groups in the $\omega$-position (e.g. amino-substituted and unfunctionalised analogues). Selected fatty acid structures will then be used for the synthesis of muraymycin analogues with potentially improved cellular uptake and thus also with enhanced biological activities. Overall, it is anticipated that these results will enable the design of muraymycin analogues with optimised biological profiles. This strategy might also have the potential to be employed within SAR studies on other lipidated natural products, ${ }^{37-41}$ and it might generally stimulate the functional analysis of medicinally relevant natural products based on simplified, chemically more tractable model systems.

\section{Experimental}

\section{Synthesis}

General methods. Azide-labelled AlexaFluor 488 was obtained from Life Technologies. All other chemicals were purchased from standard suppliers. $\mathrm{SiO}_{2}$-supported $\mathrm{NaIO}_{4}$ was prepared according to an established procedure. ${ }^{42,43}$ Reactions involving oxygen and/or moisture sensitive reagents were carried out under an atmosphere of argon using anhydrous solvents. Anhydrous solvents were obtained in the following manner: $\mathrm{CH}_{2} \mathrm{Cl}_{2}$ was dried over $\mathrm{CaH}_{2}$ and distilled, pyridine was dried over $\mathrm{CaH}_{2}$ and distilled, DMF was dried over activated molecular sieves (4 ̊) and degassed. All other solvents were of technical quality and distilled prior to their use, and deionised water was used throughout. Column chromatography was carried out on silica gel 60 (0.040$0.063 \mathrm{~mm}, 230-400$ mesh ASTM, VWR) under flash conditions. TLC was performed on aluminium plates precoated with silica gel $60 F_{254}$ (VWR). Visualisation of the spots was carried out using UV light $(254 \mathrm{~nm})$ and/or staining under heating $\left(\mathrm{KMnO}_{4}\right.$ staining solution: $1 \mathrm{~g} \mathrm{KMnO}_{4}, 6 \mathrm{~g} \mathrm{~K} \mathrm{~K}_{2} \mathrm{CO}_{3}$ and $1.5 \mathrm{~mL} 1.25 \mathrm{M} \mathrm{NaOH}$ solution, all dissolved in $100 \mathrm{~mL}$ $\mathrm{H}_{2} \mathrm{O}$ ). Preparative HPLC was performed on a VWR-Hitachi system equipped with an L-2300 pump, an L-2200 autosampler, an L-2300 column oven $\left(25^{\circ} \mathrm{C}\right)$, an L-2455
Diode Array Detector (DAD) and a LiChroCart ${ }^{\mathrm{TM}}$ column $(4 \times$ $125 \mathrm{~mm}$ ) containing reversed phase silica gel Purospher ${ }^{\mathrm{TM}}$ RP18e $(5 \mu \mathrm{m})$ purchased from VWR. $300 \mathrm{MHz}^{1}{ }^{1} \mathrm{H}$ and 75 MHz-, $76 \mathrm{MHz}$, , and $126 \mathrm{MHz}^{-13} \mathrm{C}$ NMR spectra were recorded on Varian MERCURY 300, UNITY 300 and INOVA 500 spectrometers. All ${ }^{13} \mathrm{C}$ NMR spectra are ${ }^{1} \mathrm{H}$-decoupled. All spectra were recorded at room temperature except of samples in DMSO- $d_{6}$ (standard $35{ }^{\circ} \mathrm{C}$ ) and where indicated otherwise and were referenced internally to solvent reference frequencies wherever possible. Chemical shifts $(\delta)$ are quoted in ppm, and coupling constants $(J)$ are reported in Hz. Assignment of signals was carried out using ${ }^{1} \mathrm{H},{ }^{1} \mathrm{H}$-COSY, HSQC and $\mathrm{HMBC}$ spectra obtained on the spectrometers mentioned above. Low resolution ESI mass spectrometry was performed on a Varian MAT 311 A spectrometer operating in positive or negative ionisation mode. High resolution (HR) ESI mass spectrometry was carried out on a Bruker microTOF spectrometer or a Bruker 7T FTICR APEX IV spectrometer. Melting points (mp) were measured on a Büchi instrument and are not corrected. Infrared spectroscopy (IR) was performed on a Jasco FT/IR-4100 spectrometer equipped with an integrated ATR unit (GladiATR ${ }^{\mathrm{TM}}$, PIKE Technologies). Wavenumbers ( $v$ ) are quoted in $\mathrm{cm}^{-1}$. UV spectroscopy was carried out on a Jasco V-630 spectrometer.

Propargyl 13-( $\mathrm{N}$-hydroxyguanidino)-tridecanoate 10. $1 \mathrm{H}$ Pyrazole-1-carboxamidine hydrochloride 19 (72 $\mathrm{mg}, \quad 0.49$ mmol) and $\mathrm{NEt}_{3}(0.14 \mathrm{~mL}, 0.10 \mathrm{~g}, 1.00 \mathrm{mmol})$ were added to a solution of $N$-alkyl hydroxylamine $18(100 \mathrm{mg}, 0.353 \mathrm{mmol})$ in DMF ( $2 \mathrm{~mL}$ ) and the reaction mixture was stirred at $\mathrm{rt}$ for $15 \mathrm{~h}$. The solvent was evaporated under reduced pressure and the resultant residue was dissolved in sat. $\mathrm{NH}_{4} \mathrm{Cl}$ solution $(5 \mathrm{~mL})$. The aqueous solution was extracted with $\mathrm{Et}_{2} \mathrm{O}$ (3 $\times 10 \mathrm{~mL}$ ) and the combined organics were dried over $\mathrm{Na}_{2} \mathrm{SO}_{4}$ and evaporated under reduced pressure. The resultant crude product was purified by column chromatography $\left(\mathrm{CH}_{2} \mathrm{Cl}_{2}-\right.$ $\mathrm{MeOH}, 9: 1 \rightarrow 1: 1)$ to give $10(53 \mathrm{mg}, 47 \%)$ as a colourless solid; mp $77{ }^{\circ} \mathrm{C}$; TLC $R_{\mathrm{f}} 0.28\left(\mathrm{CH}_{2} \mathrm{Cl}_{2}-\mathrm{MeOH}, 4: 1\right)$; IR (ATR) $v_{\max } / \mathrm{cm}^{-1} 2920,2848,1728,1626,1468,1166$ and $1105 ; \delta_{\mathrm{H}}$ (300 MHz, DMSO- $d_{6}$ ) 1.09-1.36 (16 H, m, 4- $\left.\mathrm{H}_{2}-11-\mathrm{H}_{2}\right)$, 1.41$1.65\left(4 \mathrm{H}, \mathrm{m}, 3-\mathrm{H}_{2}, 12-\mathrm{H}_{2}\right), 2.30\left(2 \mathrm{H}, \mathrm{t}, J\right.$ 7.3, 2- $\left.\mathrm{H}_{2}\right), 3.50(1 \mathrm{H}$, d, $\left.J 2.5,3^{\prime}-\mathrm{H}\right), 3.54$ (2 H, t, J 7.0, 13- $\mathrm{H}_{2}$ ), 4.66 (2 H, d, J 2.5, 1'$\mathrm{H}_{2}$ ) and $7.61\left(4 \mathrm{H}\right.$, br s, NH, OH); $\delta_{\mathrm{C}}\left(76 \mathrm{MHz}, \mathrm{DMSO}-d_{6}\right)$ 24.3, 25.7, 25.7, 28.2, 28.5, 28.7, 28.8, 28.9, 33.1, 50.7, 51.4, 77.4, 78.4, 157.7 and 172.1; $\mathrm{m} / \mathrm{z}\left(\mathrm{ESI}^{+}\right) 326.2\left(\mathrm{M}+\mathrm{H}^{+}\right) ; \mathrm{m} / \mathrm{z}$ $\left(\right.$ HR-ESI $\left.^{+}\right) 326.2438\left(\mathrm{M}+\mathrm{H}^{+}, \mathrm{C}_{17} \mathrm{H}_{32} \mathrm{~N}_{3} \mathrm{O}_{3}\right.$ requires 326.2438).

AlexaFluor 488 lipid side chain conjugate 11. A solution of azide-labelled AlexaFluor 4889 (50 mM in DMF, $2.0 \mu \mathrm{L}, 0.10$ $\mu \mathrm{mol} 9$ ), a solution of lipid side chain propargyl ester 10 (50 $\mathrm{mM}$ in $\mathrm{MeOH}, 8.0 \mu \mathrm{L}, 0.40 \mu \mathrm{mol} 10$ ), a solution of sodium L-ascorbate $(20 \mathrm{mM}$ in water, $4.0 \mu \mathrm{L}, 80 \mathrm{nmol}$ sodium L-ascorbate), a solution of $\mathrm{CuSO}_{4}(10 \mathrm{mM}$ in water, $4.0 \mu \mathrm{L}, 40$ nmol $\left.\mathrm{CuSO}_{4}\right), \mathrm{MeOH}(6 \mu \mathrm{L})$ and Triton X-100 (10\% in water, $48 \mu \mathrm{L})$ were mixed and stirred in a ThermoMixer $\left(50{ }^{\circ} \mathrm{C}, 200\right.$ $\mathrm{rpm}$ ) for $15 \mathrm{~h}$. The reaction mixture was then directly purified by preparative HPLC (MeCN-water $(+0.01 \%$ TFA), 15:85 $\rightarrow$ $\left.50: 50,1.0 \mathrm{~mL} \mathrm{~min}^{-1}\right)$. Product-containing fractions were 
pooled, and the solvent was removed with an Eppendorf Concentrator 5301 to give 11 (estimated from UV-Vis data: 9.0 $\mathrm{nmol})$ as a red solid; preparative HPLC $t_{\mathrm{R}} 13.3 \mathrm{~min} ; \mathrm{m} / z$ $\left(\mathrm{ESI}^{+}\right)$984.3 $\left(\mathrm{M}+\mathrm{H}^{+}\right)$and $1006.3\left(\mathrm{M}+\mathrm{Na}^{+}\right) ; \mathrm{m} / z\left(\mathrm{HR}-\mathrm{ESI}^{+}\right)$ 984.3594 ( $\mathrm{M}+\mathrm{H}^{+}, \mathrm{C}_{44} \mathrm{H}_{58} \mathrm{~N}_{9} \mathrm{O}_{13} \mathrm{~S}_{2}$ requires 984.3590).

AlexaFluor 488 acetyl conjugate 12. A solution of azidelabelled AlexaFluor 4889 (5 mM in DMF, $20 \mu \mathrm{L}, 0.10 \mu \mathrm{mol}$ 9), a solution of propargyl acetate 20 ( $1 \mathrm{M}$ in $\mathrm{MeOH}, 14 \mu \mathrm{L}$, $14 \mu \mathrm{mol} 20$ ), a solution of sodium L-ascorbate $(20 \mathrm{mM}$ in water, $10 \mu \mathrm{L}, 0.20 \mu \mathrm{mol}$ sodium L-ascorbate), a solution of $\mathrm{CuSO}_{4}\left(10 \mathrm{mM}\right.$ in water, $\left.10 \mu \mathrm{L}, 0.10 \mu \mathrm{mol} \mathrm{CuSO}{ }_{4}\right)$ and Triton $\mathrm{X}-100(10 \%$ in water, $48 \mu \mathrm{L})$ were mixed and stirred in a ThermoMixer $\left(10^{\circ} \mathrm{C}, 200 \mathrm{rpm}\right)$ for $17 \mathrm{~h}$. The reaction mixture was then directly purified by preparative HPLC (MeCN-water $\left(+0.01 \%\right.$ TFA), 15:85 $\left.\rightarrow 50: 50,1.0 \mathrm{~mL} \mathrm{~min}{ }^{-1}\right)$. Productcontaining fractions were pooled, and the solvent was removed with an Eppendorf Concentrator 5301 to give 12 (estimated from UV-Vis data: $32 \mathrm{nmol}$ ) as a red solid; preparative HPLC $t_{\mathrm{R}} 6.8 \mathrm{~min} ; \mathrm{m} / z\left(\mathrm{ESI}^{-}\right) 755.1\left(\mathrm{M}-\mathrm{H}^{+}\right) ; \mathrm{m} / z(\mathrm{HR}-$ $\left.\mathrm{ESI}^{-}\right) 755.1446\left(\mathrm{M}-\mathrm{H}^{+}, \mathrm{C}_{32} \mathrm{H}_{31} \mathrm{~N}_{6} \mathrm{O}_{12} \mathrm{~S}_{2}\right.$ requires 755.1447).

13,14-Dihydroxybehenic acid 14. A solution of $\mathrm{H}_{2} \mathrm{O}_{2}(30 \%$ in water, $15.0 \mathrm{~mL}, 16.7 \mathrm{~g}, 147 \mathrm{mmol}_{2} \mathrm{O}_{2}$ ) in formic acid (50 $\mathrm{mL}$ ) was added dropwise to a suspension of erucic acid 13 $(5.00 \mathrm{~g}, 14.8 \mathrm{mmol})$ in formic acid $(50 \mathrm{~mL})$ and stirred at $\mathrm{rt}$ for $23 \mathrm{~h}$. Excess $\mathrm{H}_{2} \mathrm{O}_{2}$ was destroyed with $\mathrm{Na}_{2} \mathrm{SO}_{3}$ (negative iodine starch test) and the solvent was evaporated under reduced pressure. The resultant residue was dissolved in $\mathrm{KOH}$ solution (1 M, $100 \mathrm{~mL}$ ) and heated under reflux for $4 \mathrm{~h}$. The reaction mixture was then acidified with $\mathrm{HCl}(2 \mathrm{M}, 100$ $\mathrm{mL})$ and the aqueous layer was extracted with EtOAc $(3 \times 100$ $\mathrm{mL}$ ). The combined organics were dried over $\mathrm{Na}_{2} \mathrm{SO}_{4}$ and the solvent was evaporated under reduced pressure to give 14 (5.17 g, 94\%) as a colourless solid; mp $110{ }^{\circ} \mathrm{C}$; IR (ATR) $v_{\max } / \mathrm{cm}^{-1}$ 3332, 3254, 2912, 2846, 1703, 1467, 720 and 656; $\delta_{\mathrm{H}}\left(300 \mathrm{MHz}, \mathrm{DMSO}-d_{6}\right) 0.68\left(3 \mathrm{H}, \mathrm{t}, J\right.$ 6.7, 22- $\left.\mathrm{H}_{3}\right), 1.15-1.33$ (28 H, m, 4- $\left.\mathrm{H}_{2}-11-\mathrm{H}_{2}, 16-\mathrm{H}_{2}-21-\mathrm{H}_{2}\right), 1.34-1.43$ (4 H, m, 12- $\mathrm{H}_{2}$, 15- $\mathrm{H}_{2}$ ), 1.44-1.57 (2 H, m, 3- $\left.\mathrm{H}_{2}\right), 2.18$ (2 H, t, J 7.3, 2- $\mathrm{H}_{2}$ ), 3.15-3.25 (2 H, m, 13- H, 14-H) and $4.06(2 \mathrm{H}$, br s, OH $) ; \delta_{\mathrm{C}}$ (75 MHz, DMSO- $d_{6}$ ) 13.8, 22.0, 28.5, 28.6, 28.7, 28.8, 28.9, $28.9,29.0,29.0,29.2,31.2,24.4,25.5,32.3,33.6,73.0$ and 174.3; $\mathrm{m} / \mathrm{z}\left(\mathrm{ESI}^{+}\right) 373.3\left(\mathrm{M}+\mathrm{H}^{+}\right)$and $395.4\left(\mathrm{M}+\mathrm{Na}^{+}\right) ; \mathrm{m} / z$ $\left(\mathrm{HR}-\mathrm{ESI}^{+}\right) 373.3311\left(\mathrm{M}+\mathrm{H}^{+}, \mathrm{C}_{22} \mathrm{H}_{45} \mathrm{O}_{4}\right.$ requires 373.3312).

Propargyl 13,14-dihydroxybehenoate 15. To a solution of carboxylic acid 14 (1.71 g, $4.56 \mathrm{mmol})$, propargylic alcohol (5.30 $\mathrm{mL}, 91.7 \mathrm{mmol}$ ) and 4-(dimethylamino)-pyridine (DMAP, $59 \mathrm{mg}, 0.48 \mathrm{mmol})$ in $\mathrm{CH}_{2} \mathrm{Cl}_{2}(100 \mathrm{~mL})$, dicyclohexyl carbodiimide (DCC, $1.22 \mathrm{~g}, 5.91 \mathrm{mmol}$ ) was added. The reaction mixture was stirred at $\mathrm{rt}$ for $20 \mathrm{~h}$ and then diluted with sat. $\mathrm{NH}_{4} \mathrm{Cl}$ solution $(90 \mathrm{~mL})$. The aqueous layer was extracted with $\mathrm{CH}_{2} \mathrm{Cl}_{2}(2 \times 90 \mathrm{~mL})$. The combined organics were washed with water $(1 \times 90 \mathrm{~mL})$, dried over $\mathrm{Na}_{2} \mathrm{SO}_{4}$ and evaporated under reduced pressure. The resultant crude product was purified by column chromatography (petroleum etherEtOAc, $3: 1)$ to give 15 (980 $\mathrm{mg}, 52 \%$ ) as a colourless solid; $\mathrm{mp} 64{ }^{\circ} \mathrm{C}$; TLC $R_{\mathrm{f}} 0.36$ (petroleum ether-EtOAc, 2:1); IR (ATR) $v_{\max } / \mathrm{cm}^{-1} 3300,2913,2846,1740,1467,1170,721$ and
640; $\delta_{\mathrm{H}}\left(300 \mathrm{MHz}, \mathrm{DMSO}-d_{6}\right) 0.84\left(3 \mathrm{H}, \mathrm{t}, J 6.6,22-\mathrm{H}_{3}\right), 1.12-$ $1.46\left(32 \mathrm{H}, \mathrm{m}, 4-\mathrm{H}_{2}-12-\mathrm{H}_{2}, 15-\mathrm{H}_{2}-21-\mathrm{H}_{2}\right), 1.47-1.63(2 \mathrm{H}, \mathrm{m}$, $\left.3-\mathrm{H}_{2}\right), 2.28$ ( $2 \mathrm{H}, \mathrm{t}, J$ 7.4, 2- $\mathrm{H}_{2}$ ), 3.13 (1 H, t, J 2.4, 3'-H), 3.143.27 (2 H, m, 13-H, 14-H), 3.89 (2 H, d, J 4.0, OH) and 4.61 (2 $\left.\mathrm{H}, \mathrm{d}, J 2.4,1^{\prime}-\mathrm{H}_{2}\right) ; \delta_{\mathrm{C}}\left(76 \mathrm{MHz}, \mathrm{DMSO}-d_{6}\right)$ 13.6, 22.0, 25.3, 28.3, 28.5, 28.6, 28.7, 28.9, 28.9, 28.9, 29.0, 29.1, 31.2, 32.6, 24.2, 33.1, 51.1, 73.1, 77.8, 78.5 and 171.7; $\mathrm{m} / \mathrm{z}\left(\mathrm{ESI}^{+}\right) 433.4$ $\left(\mathrm{M}+\mathrm{Na}^{+}\right) ; \mathrm{m} / z\left(\mathrm{HR}-\mathrm{ESI}^{+}\right) 433.3288\left(\mathrm{M}+\mathrm{Na}^{+}, \mathrm{C}_{25} \mathrm{H}_{46} \mathrm{NaO}_{4}\right.$ requires 433.3288 ).

Propargyl 13-oxotridecanoate 16. To a solution of diol 15 (857 $\mathrm{mg}, 2.09 \mathrm{mmol})$ in $\mathrm{CH}_{2} \mathrm{Cl}_{2}(20 \mathrm{~mL}), \mathrm{SiO}_{2}$-supported $\mathrm{NaIO}_{4}$ (ref. 42 and 43) (0.610 mmol g${ }^{-1}, 5.14 \mathrm{~g}, 3.14 \mathrm{mmol}$ $\mathrm{NaIO}_{4}$ ) was added. The resultant suspension was stirred at $\mathrm{rt}$ for $1 \mathrm{~h}$ and then filtered. The filtrate was evaporated under reduced pressure. The resultant crude product was purified by column chromatography (petroleum ether-EtOAc, 6:1) to give $16(473 \mathrm{mg}, 85 \%)$ as a colourless oil; TLC $R_{\mathrm{f}} 0.29$ (petroleum ether-EtOAc, 6:1); IR (ATR) $v_{\max } / \mathrm{cm}^{-1} 2924,2853,1738$, $1724,1157,1106,1025,997$ and 666; $\delta_{\mathrm{H}}\left(300 \mathrm{MHz}, \mathrm{DMSO}-d_{6}\right)$ 1.15-1.60 (18 H, m, 3- $\left.\mathrm{H}_{2}-11-\mathrm{H}_{2}\right), 2.32\left(2 \mathrm{H}, \mathrm{t}, J\right.$ 7.3, 2- $\left.\mathrm{H}_{2}\right), 2.40$ (2 H, td, $J$ 7.2, $J$ 1.6, 12- $\mathrm{H}_{2}$ ), 3.47 (1 H, t, $J$ 2.2, 3'-H), 4.67 (2 $\left.\mathrm{H}, \mathrm{d}, J 2.2,1^{\prime}-\mathrm{H}_{2}\right)$ and $9.66(1 \mathrm{H}, \mathrm{t}, J 1.6,13-\mathrm{H}) ; \delta_{\mathrm{C}}(76 \mathrm{MHz}$, DMSO- $\left.d_{6}\right) 24.2,28.2,28.4,28.5,28.5,28.6,28.7,28.7,28.8$, 33.1, 42.9, 51.3, 77.2, 78.4, 172.0 and 203.3; $\mathrm{m} / \mathrm{z}\left(\mathrm{ESI}^{+}\right) 289.2$ $\left(\mathrm{M}+\mathrm{Na}^{+}\right) ; m / z\left(\mathrm{HR}^{-E^{+}}{ }^{+}\right) 289.1778\left(\mathrm{M}+\mathrm{Na}^{+}, \mathrm{C}_{16} \mathrm{H}_{26} \mathrm{NaO}_{3}\right.$ requires 289.1774).

Propargyl 13-hydroxyiminotridecanoate 17. A solution of aldehyde 16 (359 mg, $1.35 \mathrm{mmol}$ ) and hydroxylamine hydrochloride (470 mg, $6.76 \mathrm{mmol})$ in EtOH (5 mL) and pyridine (5 $\mathrm{mL}$ ) was stirred in the presence of molecular sieve $(3 \AA)$ at rt for $46 \mathrm{~h}$. The reaction mixture was filtered through a short pad of celite and the solvent of the filtrate was evaporated under reduced pressure. The resultant crude product was purified by column chromatography (petroleum ether-EtOAc, $4: 1)$ to give 17 (349 $\mathrm{mg}, 92 \%)$ as a mixture of $E / Z$-isomers as a colourless solid; TLC $R_{\mathrm{f}} 0.22$ (petroleum ether-EtOAc, $4: 1$ ); $\delta_{\mathrm{H}}\left(300 \mathrm{MHz}, \mathrm{C}_{6} \mathrm{D}_{6}\right) 1.05-1.31\left(16 \mathrm{H}, \mathrm{m}, 4-\mathrm{H}_{2}-11-\mathrm{H}_{2}\right), 1.43-$ $1.61\left(2 \mathrm{H}, \mathrm{m}, 3-\mathrm{H}_{2}\right), 2.01(1 \mathrm{H}, \mathrm{t}, J$ 2.4, 3'-H), 2.06 ( $2 \mathrm{H}, \mathrm{t}, J$ 7.4, $2-\mathrm{H}_{2}$ ), 2.31 ( $2 \mathrm{H}, \mathrm{td}, J$ 7.1, $J$ 5.4, 12- $\mathrm{H}_{2}$ ), 4.44 (2 H, d, $J 2.4,1^{\prime}-$ $\left.\mathrm{H}_{2}\right), 6.51(1 \mathrm{H}, \mathrm{t}, J 5.4,13-\mathrm{H})$ and $8.94(1 \mathrm{H}, \mathrm{br} \mathrm{s}, \mathrm{OH}) ; \delta_{\mathrm{C}}(126$ $\left.\mathrm{MHz}, \mathrm{C}_{6} \mathrm{D}_{6}\right)$ 25.2, 25.4, 26.4, 29.4, 29.7, 29.7, 29.8, 29.9, 29.9, 30.0, 34.1, 51.6, 74.8, 78.4, 152.2 and 172.2; $\mathrm{m} / \mathrm{z}\left(\mathrm{ESI}^{+}\right) 304.2$ $\left(\mathrm{M}+\mathrm{Na}^{+}\right) ; m / z\left(\mathrm{HR}^{\left.-\mathrm{ESI}^{+}\right)} 304.1884\left(\mathrm{M}+\mathrm{Na}^{+}, \mathrm{C}_{16} \mathrm{H}_{27} \mathrm{NNaO}_{3}\right.\right.$ requires 304.1883).

Propargyl 13-hydroxyaminotridecanoate 18. $\mathrm{NaBH}_{3} \mathrm{CN}$ $(1.18 \mathrm{~g}, 18.8 \mathrm{mmol})$ and freshly prepared $\mathrm{HCl}$ in $\mathrm{MeOH}(1 \mathrm{M})$ were added alternately and portionwise to a solution of oxime 17 (500 mg, $1.78 \mathrm{mmol}$ ) and methyl orange (small amount, indicator) in i-PrOH $(25 \mathrm{~mL})$ until the reaction mixture retained a pink color. The reaction mixture was stirred at $\mathrm{rt}$ for $24 \mathrm{~h}$ and then neutralised with $\mathrm{NEt}_{3}$ and evaporated under reduced pressure. The resultant residue was dissolved in EtOAc $(50 \mathrm{~mL})$, washed with sat. $\mathrm{NaHCO}_{3}(2 \times 50 \mathrm{~mL})$ and brine $(1 \times 50 \mathrm{~mL})$, dried over $\mathrm{Na}_{2} \mathrm{SO}_{4}$ and evaporated under reduced pressure. The resultant crude product was purified by column chromatography (EtOAc) to give 18 (334 mg, 66\%) 
as a colourless solid; mp $62{ }^{\circ} \mathrm{C}$; TLC $R_{\mathrm{f}} 0.35$ (EtOAc); IR (ATR) $v_{\max } / \mathrm{cm}^{-1}$ 3299, 2916, 2848, 1740, 1464, 1390, 1276, 1225, 1199 and $1175 ; \delta_{\mathrm{H}}\left(300 \mathrm{MHz}, \mathrm{CDCl}_{3}\right) 1.18-1.38(16 \mathrm{H}, \mathrm{m}$, 4- $\left.\mathrm{H}_{2}-11-\mathrm{H}_{2}\right), 1.46-1.69\left(4 \mathrm{H}, \mathrm{m}, 3-\mathrm{H}_{2}, 12-\mathrm{H}_{2}\right), 2.34(2 \mathrm{H}, \mathrm{t}, J$ 7.5, 2- $\mathrm{H}_{2}$ ), 2.46 (1 H, t, J 2.5, 3'-H), 2.92 (2 H, t, J 7.3, 13- $\mathrm{H}_{2}$ ), $4.66\left(2 \mathrm{H}, \mathrm{d}, J 2.5,1^{\prime}-\mathrm{H}_{2}\right)$ and $5.83\left(2 \mathrm{H}\right.$, br s, NH, OH); $\delta_{\mathrm{C}}$ (126 $\mathrm{MHz}, \mathrm{CDCl}_{3}$ ) 24.8, 26.7, 27.1, 29.1, 29.1, 29.2, 29.4, 29.5, 29.5, 29.6, 34.0, 51.7, 53.6, 74.7, 77.8 and 172.8; $\mathrm{m} / \mathrm{z}\left(\mathrm{ESI}^{+}\right)$ $284.2\left(\mathbf{M}+\mathrm{H}^{+}\right)$and $306.2\left(\mathbf{M}+\mathrm{Na}^{+}\right) ; m / z\left(\right.$ HR-ESI $\left.{ }^{+}\right) 284.2223$ $\left(\mathrm{M}+\mathrm{H}^{+}, \mathrm{C}_{16} \mathrm{H}_{30} \mathrm{NO}_{3}\right.$ requires 284.2220).

\section{Membrane partitioning assay}

Materials. 1-Palmitoyl-2-oleoyl-sn-glycero-3-phosphocholine (POPC), 1-palmitoyl-2-oleoyl-sn-glycero-3-phosphoethanolamine (POPE), and 1,2-distearoyl-sn-glycero-3-phosphoethanolamine- $N$-[biotinyl(polyethylene glycol)-2000] (DSPE-PEG2000biotin) were purchased from Avanti Polar Lipids. Sulforhodamine 101 1,2-dihexadecanoyl-sn-glycero-3-phosphoethanolL-amine-triethyl ammonium salt (Texas Red DHPE) was obtained from Sigma-Aldrich.

Preparation of giant unilamellar vesicles (GUVs). GUVs were prepared by an electroformation method. Briefly, $25 \mu \mathrm{L}$ of lipid stock solution $\left(2 \mathrm{mg} \mathrm{mL}{ }^{-1}\right.$ in $\mathrm{CHCl}_{3}$ ) were applied on each of two indium tin oxide (ITO) coated glass slides at rt. The evaporation of $\mathrm{CHCl}_{3}$ was accelerated by incubation under vacuum at rt for at least $3 \mathrm{~h}$. To fix GUVs to avidincoated silicon substrates, 0.5 mol\% of DSPE-PEG2000-biotin were added to the lipid stock solution. For fluorescence visualisation of the vesicular membranes by confocal laser scanning microscopy, GUVs were labelled with 0.5 mol\% Texas Red DHPE. The lipid film was rehydrated with $1 \mathrm{~mL}$ of $0.3 \mathrm{M}$ sucrose solution. GUVs were formed by the application of an AC field at $3 \mathrm{~V}$ and $5 \mathrm{~Hz}$ (sinusoidal wave) for $3 \mathrm{~h}$.

Membrane partitioning assay. The potential binding of AF488 conjugates 11 and 12 to GUV membranes and their possible translocation was investigated by an upright confocal laser scanning fluorescence microscope. GUVs were fixed to an avidin-coated silicon substrate via avidin-biotin interaction. First, the substrate was cleaned with i-PrOH and water. Then, it was rendered hydrophilic by incubating it in a $\mathrm{H}_{2} \mathrm{O}-$ $\mathrm{NH}_{3}-\mathrm{H}_{2} \mathrm{O}_{2}(5: 1: 1)$ solution at $70{ }^{\circ} \mathrm{C}$ for $20 \mathrm{~min}$. Afterwards, the silicon wafer was incubated with $50 \mu \mathrm{M}$ avidin solution in phosphate buffered saline (PBS, $2.7 \mathrm{mM} \mathrm{KCl,} 136.9 \mathrm{mM}$ $\mathrm{NaCl}, 1.5 \mathrm{mM} \mathrm{KH} \mathrm{PO}_{4}, 8.1 \mathrm{mM} \mathrm{Na} \mathrm{HPO}_{4}, \mathrm{pH} \mathrm{7.4)} \mathrm{for} 1 \mathrm{~h}$ and rinsed with PBS to obtain high avidin surface coverage. Avidin-coated silicon substrates were incubated with DSPEPEG2000-biotin doped GUVs for at least $15 \mathrm{~min}$ to allow for the GUVs to bind to avidin. Subsequently, $0.8 \mu \mathrm{M}$ AF488 conjugate 11 or 12 in PBS was added and the sample was analysed by confocal laser scanning microscopy.

Confocal laser scanning microscopy. Fluorescence images were taken with a confocal laser scanning microscope (LSM 710, Carl Zeiss, Jena, Germany) equipped with a water immersion objective W Plan-Apochromat $63 \times / 1.0$ n.a. (Zeiss). AlexaFluor 488 and Texas Red were excited at $\lambda_{\mathrm{ex}}=488 \mathrm{~nm}$ and $563 \mathrm{~nm}$, respectively. Emission was detected at $\lambda_{\mathrm{em}}=$ 495-538 $\mathrm{nm}$ and 633-690 $\mathrm{nm}$, respectively.

\section{Acknowledgements}

The authors thank the Deutsche Forschungsgemeinschaft (DFG, SFB 803 "Functionality controlled by organization in and between membranes") and the Fonds der Chemischen Industrie (FCI, Sachkostenzuschuss) for financial support.

\section{Notes and references}

1 G. Taubes, Science, 2008, 321, 356-361.

2 M. A. Cooper and D. Shlaes, Nature, 2011, 472, 32.

3 K.-I. Kimura and T. D. H. Bugg, Nat. Prod. Rep., 2003, 20, 252-273.

4 M. Winn, R. J. M. Goss, K.-I. Kimura and T. D. H. Bugg, Nat. Prod. Rep., 2010, 27, 279-304.

5 C. Dini, Curr. Top. Med. Chem., 2005, 5, 1221-1236.

6 T. D. H. Bugg, A. J. Lloyd and D. I. Roper, Infect. Disord.: Drug Targets, 2006, 6, 85-106.

7 A. J. Lloyd, P. E. Brandish, A. M. Gilbey and T. D. H. Bugg, J. Bacteriol., 2004, 186, 1747-1757.

8 M. T. Rodolis, A. Mihalyi, A. O'Reilly, J. Slikas, D. I. Roper, R. E. W. Hancock and T. D. H. Bugg, ChemBioChem, 2014, 15, 1300-1308.

9 M. T. Rodolis, A. Mihalyi, C. Ducho, K. Eitel, B. Gust, R. J. M. Goss and T. D. H. Bugg, Chem. Commun., 2014, 50, 13023-13025.

10 L. A. McDonald, L. R. Barbieri, G. T. Carter, E. Lenoy, J. Lotvin, P. J. Petersen, M. M. Siegel, G. Singh and R. T. Williamson, J. Am. Chem. Soc., 2002, 124, 10260-10261.

11 Y.-I. Lin, Z. Li, G. D. Francisco, L. A. McDonald, R. A. Davis, G. Singh, Y. Yang and T. S. Mansour, Bioorg. Med. Chem. Lett., 2002, 12, 2341-2344.

12 A. Yamashita, E. Norton, P. J. Petersen, B. A. Rasmussen, G. Singh, Y. Yang, T. S. Mansour and D. M. Ho, Bioorg. Med. Chem. Lett., 2003, 13, 3345-3350.

13 T. Tanino, S. Ichikawa, B. Al-Dabbagh, A. Bouhss, H. Oyama and A. Matsuda, ACS Med. Chem. Lett., 2010, 1, 258-262.

14 T. Tanino, B. Al-Dabbagh, D. Mengin-Lecreulx, A. Bouhss, H. Oyama, S. Ichikawa and A. Matsuda, J. Med. Chem., 2011, 54, 8421-8439.

15 Y. Takeoka, T. Tanino, M. Sekiguchi, S. Yonezawa, M. Sakagami, F. Takahashi, H. Togame, Y. Tanaka, H. Takemoto, S. Ichikawa and A. Matsuda, ACS Med. Chem. Lett., 2014, 5, 556-560.

16 H. C. Kolb, M. G. Finn and K. B. Sharpless, Angew. Chem., 2001, 113, 2056-2075 (Angew. Chem., Int. Ed., 2001, 40, 2004-2021).

17 V. V. Rostovtsev, L. G. Green, V. V. Fokin and K. B. Sharpless, Angew. Chem., 2002, 114, 2708-2711 (Angew. Chem., Int. Ed., 2002, 41, 2596-2599).

18 C. W. Tornoe, C. Christensen and M. Meldal, J. Org. Chem., 2002, 67, 3057-3064. 
19 A. P. Spork, S. Koppermann and C. Ducho, Synlett, 2009, 2503-2507.

20 A. P. Spork, S. Koppermann, B. Dittrich, R. Herbst-Irmer and C. Ducho, Tetrahedron: Asymmetry, 2010, 21, 763-766.

21 A. P. Spork and C. Ducho, Org. Biomol. Chem., 2010, 8, 2323-2326.

22 A. P. Spork, D. Wiegmann, M. Granitzka, D. Stalke and C. Ducho, J. Org. Chem., 2011, 76, 10083-10098.

23 M. Büschleb, M. Granitzka, D. Stalke and C. Ducho, Amino Acids, 2012, 43, 2313-2328.

24 A. P. Spork and C. Ducho, Synlett, 2013, 24, 343-346.

25 O. Ries, M. Büschleb, M. Granitzka, D. Stalke and C. Ducho, Beilstein J. Org. Chem., 2014, 10, 1135-1142.

26 A. P. Spork, M. Büschleb, O. Ries, D. Wiegmann, S. Boettcher, A. Mihalyi, T. D. H. Bugg and C. Ducho, Chem. Eur. J., 2014, 20, 15292-15297.

27 J. H. Jones, J. Pept. Sci., 2002, 8, 285-287.

28 O. Ries, A. Ochmann and C. Ducho, Synthesis, 2011, 2357-2368.

29 E. Wexselblatt, J. D. Esko and Y. Tor, J. Org. Chem., 2014, 79, 6766-6774.

30 E. Geihe Stanzl, B. M. Trantow, J. R. Vargas and P. A. Wender, Acc. Chem. Res., 2013, 46, 2944-2954.

31 C. Bechara and S. Sagan, FEBS Lett., 2013, 587, 1693-1702.
32 D. M. Copolovici, K. Langel, E. Eriste and Ü. Langel, ACS Nano, 2014, 8, 1972-1994.

33 R. Brock, Bioconjugate Chem., 2014, 25, 863-868.

34 J. Sen and A. Chaudhuri, J. Med. Chem., 2005, 48, 812-820.

35 I. Tsogas, D. Tsiourvas, G. Nounesis and C. M. Paleos, Langmuir, 2006, 22, 11322-11328.

36 S. Bera, G. G. Zhanel and F. Schweizer, J. Antimicrob. Chemother., 2010, 65, 1224-1227.

37 H. Hashizume and Y. Nishimura, in Natural Products Chemistry, ed. Atta-ur-Rahman, Elsevier, Amsterdam, 2008, vol. 35, pp. 693-751 (and references therein).

38 T. Noguchi, Y. Yasuda, T. Niida and T. Shomura, Nippon Shokubutsu Byori Gakkaiho, 1968, 34, 323-327.

39 A. Takatsuki, K. Arima and G. Tamura, J. Antibiot., 1971, 24, 215-223.

40 K. Dobashi, H. Naganawa, Y. Takahashi, T. Takita and T. Takeuchi, J. Antibiot., 1988, 41, 1533-1541.

41 A. Nemoto, Y. Hoshino, K. Yazawa, A. Ando, Y. Mikami, H. Komaki, Y. Tanaka and U. Gräfe, J. Antibiot., 2002, 55, 593-597.

42 Y.-L. Zhong and S. Chang, J. Org. Chem., 1997, 62, 2622-2624.

43 N. K. Dunlap, J. Drake, A. Ward, T. L. J. Salyard and L. Martin, J. Org. Chem., 2008, 73, 2928-2930. 